* Corresponding author Phone: +421556022514 E-mail address:peter.bigos@tuke.sk (Peter Bigoš, prof. Ing. CSC.)

Article information Article history: AMS-Volume15-No.4-00128-11 Received 21 May 2011 Accepted 18 June 2011

\section{Logistics Application on the Selected Part of Urban Mass Transportation Network in the City of Košice}

\author{
Peter Bigoš* , Daniel Kachman \\ Department of Machine Design, Transport and Logistic, Letná 9, 04200 Košice, Slovak Republic
}

\section{BIOGRAPHICAL NOTES}

Peter Bigoš, prof. Ing. CSc. Is a university professor nominated in the branch of science "Transport and Handling Engineering". He is a head of the Department of Machine Design, Transport and Logistics at the Faculty of Mechanical Engineering, Technical University of Košice. He graduated at the Faculty of Mechanical Engineering of the former Technical College in Košice (1973). Dissertation thesis he defended in 1980 and in 1983 he was designated as a docent (associate professor). In 1991 he defended his inaugural dissertation at the Technical University of Košice. In the framework of his study stages he visited TU Miskolc, VH Dresden (1981), Polytechnika Rzeszowska (1983), Ruhr Universität Bochum (1989), Imperial College London (1993), TU Budapest (1997). He is a vice-chairman of the "Common professional commission for PhD.-study" in the branch of study "Transport Machines and Machinery" and he is a member of professional commission in the branch "Forensic Engineering", too. He is also member of several advisory boards of domestic and foreign professional journals, as well as he is a guarantor of international and domestic conferences about transport machines and logistics.

\section{KEYWORDS}

Urban Mass Transportation, Logistics, Graph Theory

\section{ABSTRACT}

The submission of an article deals with urban mass transportation logistics and its application in the city of Košice. Describes the present state of knotting traffic lines on the selected part of urban mass transportation network in the city of Košice and the way how it can be determined the shortest way by the Dijkstra's algorithm. Next there was selected suitable traffic node to transmission of passengers between the particular lines. In that node there was made a harmonization of traffic lines.

\section{Introduction}

Traffic is an integral part of mans everyday life not just in the city, but also even out of the city. Toward the end of 20th and the early in 21st century there is a charge of increase individual automobile transport and loosing an interest in public passenger transport. On the roads there is increasing occurrence of traffic accident, traffic jam and congestion in the morning and afternoon peak time and the environment gets worse. Road networks in the cities weren't built on that pressure of means of transport whereupon there is necessary to find the solution how we can handle this situation. One of the ways, in which we can improve the traffic situation in the cities, is an impress upon general public the need of utilization public conveyance to transport. An advantage of urban mass transportation is that it cope great transport demands with 
bigger safety and small demands on traffic areas. It also has relatively smaller impact at the environment (in calculation on one transportation person). It is common knowledge that the base parameters which affect choose of means of transport by passenger is transfer time among the source and the object of transit, price for transportation, transportation comfort, awareness and last but not least safety and reliability of transport. On the second side transport operator tries economic and effectively satisfy passenger needs to transfer with the aim to achieve a nice profit. In [1] is shown that between long-term objectives of transport policy all bigger cities belongs increasing attractiveness public transport with the help of direction system which use telematic technologies. These telematic systems must ensure delay minimisation for means of transport of mass transport, their preference, good customer awareness about timetables and intermodal transport as well as real knowing onto stops and in the means of transport of urban mass transport.

\section{Transport lines knotting on the selected part of transportation network in the city of Košice}

Transportation network of urban mass transport is a transport roads network, which is capable to leading transport lines of periodic urban mass transportation. Public transport fails to transfer of each of passenger from the source to the objective of his journey by one mean of transport (without a transmission). In [2] author write that passenger near travelling in public transport choose such way of displacement, by which he can reach shortest transfer time regarding to transmissions and the next qualitatively criteria preferred by him. Passenger in the case of large number equal lines applies first possible transportation line in the required direction of transport. There are two types of transport lines knotting - internal and external. Internal knotting presents mutual join between particular lines of urban mass transportation. External knotting presents ties between lines of urban mass transportation and the other public transportation (public bus transportation, railway transport, air transport, etc.). When we did analysis transport lines knotting in the city of Košice we have been engaged in lines of urban mass transportation which leaves "Station square" transport junction and directed to the urban areas in Pereš, Lorinčík, Polov, Šaca, to the airport in Barca and into the plant US Steel Košice, Ltd. In Fig. 1 is shown undirected appreciated graph of the part of consideration transportation network. The vertices represent names of particular transportation network stops and the edges represents tick drive time between stops and its value include time from the ring out the signal on shutting the door at the first bus stop upon the ring out the signal on shutting the door at the next bus stop.

If we want progressing transport in the cities we must take a focus on its vital part, which represents customers - passengers. In the transport passenger represents type of the customer, which if he is not satisfied with the provided service by transport operator, will try to find some compensation instead of him. In line knotting there is necessary regards transmission time between lines, which represent walk time between output and entry stop of lines when we transfer and waiting time till

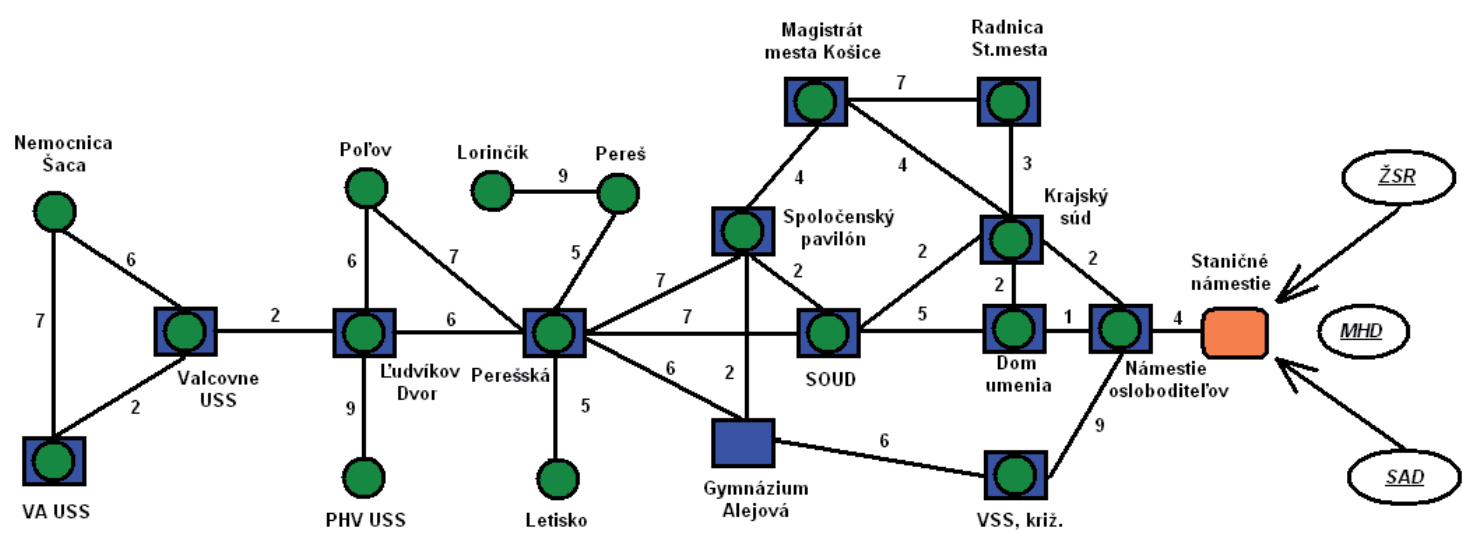

Fig. 1: Graph selected part of transportation network of urban mass transportation in Košice 
the next transportation line. If there is the same type of transport we often get in and get out on the same stop whereupon transmission time equals only waiting time till the next line. There are two types of means of transport on the exploration transport network - buses and trams. Tramway lines are creating basic transportation network and bus lines represents overlapping transportation network. Connections on those lines are direct, but there are connections, which partly intersect exploration network or they are attached on the exploration line and directed to the one of final stops. From the "SOU Dopravné" transport junction who makes border of basic transport network leads tramway line only after "VA USS" transport junction. For the next final destinations leads just bus lines makes overlapping transport network.
Direct bus lines from the station square leads only after airport bus stop and PHV USS bus stop. To knot transportation lines in the transport junctions we can divide onto the four basic types:

- To knot one transport line " $x$ " onto the other transport line "y" (Fig. 2a).

-To knot more transport lines "xi" onto the one common transport line "y" (Fig. 2b).

-To knot one transport line " $x$ " onto the more transport lines "yi" (Fig. 2c).

- To knot more transport lines "xi" on to the more transport lines "yi" (Fig. 2d).

In our case at knotting transportation lines we concentrate on the lines where passengers must transfer one or more times on the lines from station square stop to the thinking city areas.

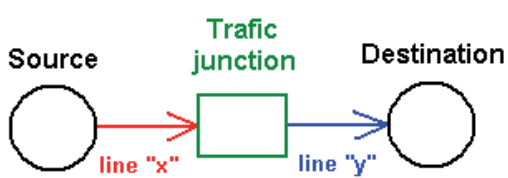

a)

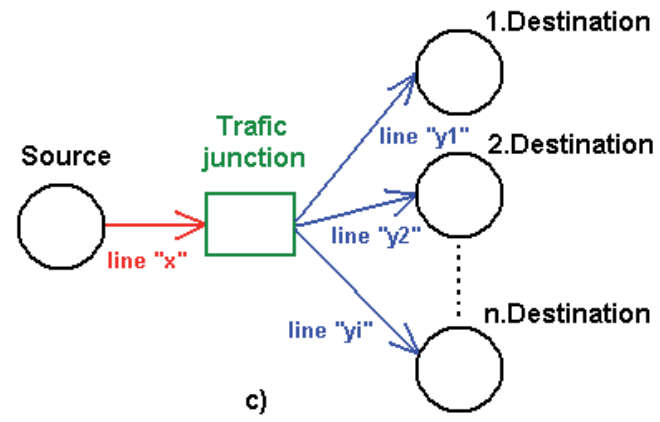

Fig. 2: Transport lines knotting at the transport junction.
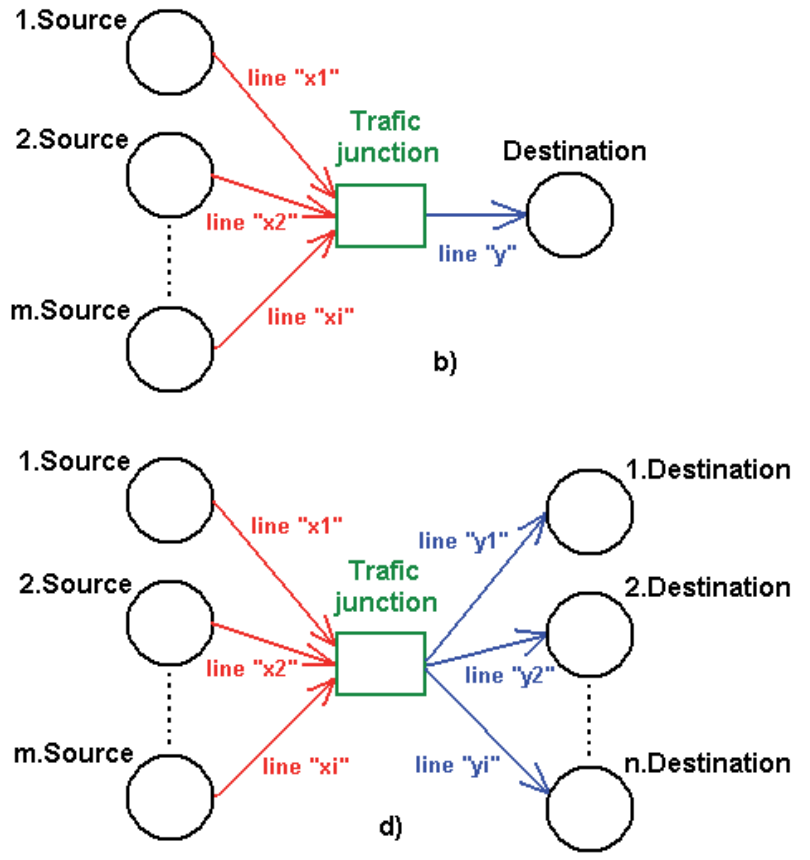

Besides periodic transport connections there are purpose made transport lines on the exploration transport network but we did not deal with because there is assumption that the lines were proposed by the request they were made. There occur three possibilities at knot transport lines. It is tramway lines mutual knot, bus lines mutual knot or their combinations. At tramway lines knotting occurred to the transfer of passenger in that trans- port junctions like "Námestie osloboditelov, Dom umenia, VSS, križ, Spoločenský pavilion and OC Optima". To knot bus lines was made in the transport junction like "Námestie osloboditel'ov, Krajský súd, Perešská and SOU Dopravné". In the case of combination tram and bus lines occurred to the transfer of passenger in the transport junction like "Námestie osloboditelov, SOU Dopravné and VSS, križ". The question is if the passenger when he comes to 
the starting transport junction (in our case station square) has enough information what type of the vehicle he can transport to the final destination of his journey. If the passenger must transfer to the next means of transport on his route how long he must wait into the come of the next vehicle? At the present the passenger does not have this type of information therefore it could be suitable make a proposal of the solution of this problem. It should help to passengers mainly to the better orientation in travelling at urban mass transportation as well as to the passenger mental comfort. In the opposite transport direction there are the same transport junctions. When we wanted to find the shortest path between two vertices on the examined graph of transportation network we used Dijkstra's algorithm. It computes length of the shortest path from the source to each of the remaining vertices in the graph. The shortest way is the way where the sum of the edges values represents minimum value. Under the algorithm term we understand progressiveness of steps, which lead us to the required solution of the given problem. In Fig. 3 is shown a final solution of Dijkstra's algorithm for monitoring transport network. At determination of shortest way we precede from the final stop till the start stop and we following the big letters of the alphabet shown with the blue colour. The number above the letter the same colour specifies total transportation time from the start transport junction (vertex " $\mathrm{A}$ " in our case). The conclusions by solving Dijkstra's algorithm in our case are that it is unnecessary speculate with the $E$ and $F$ vertices in transport lines knotting because no one of the shortest way leads over this vertices.

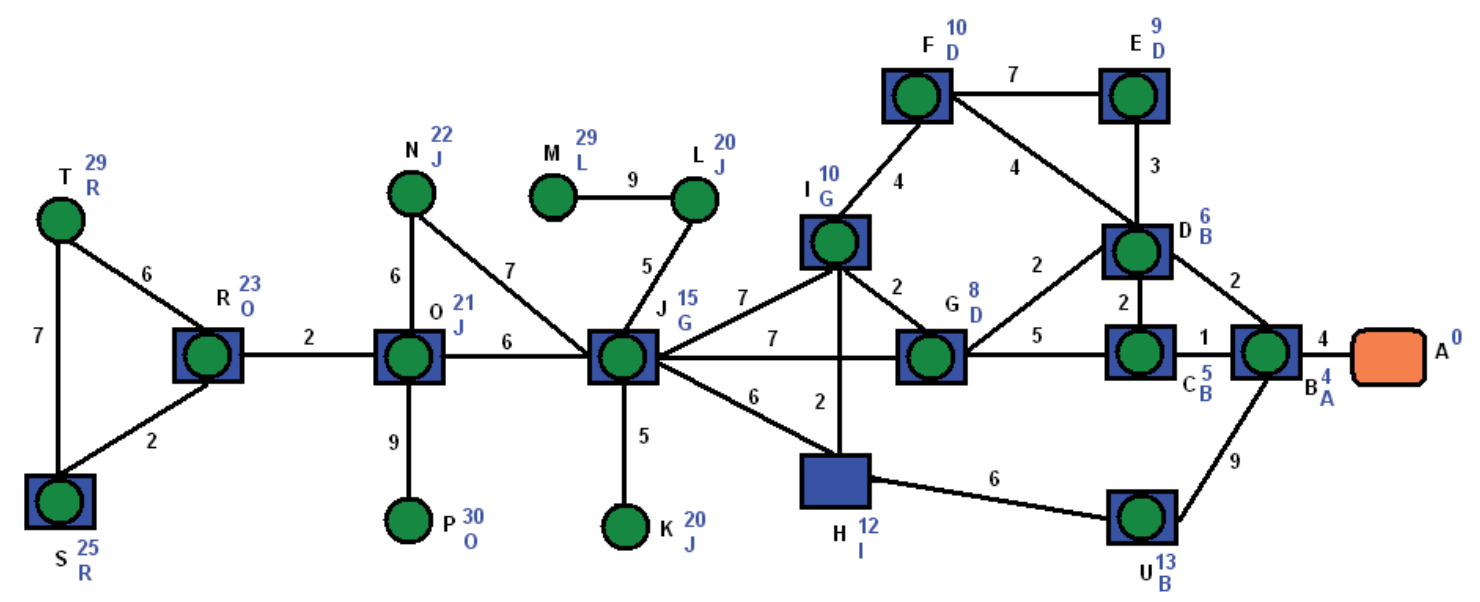

Fig. 3: Graphic presentation of Dijkstra's algorithm at the exploration part of transportation network.

\section{Means of passenger decisions at travelling}

There have been two feasible solutions at travelling for selection an appropriate manner of passenger decision [4]:

\section{- heuristic (occasional), \\ - planned.}

Heuristic solution represents that way of decision making when a passenger comes to the stop and right at that place he determines arrival time of transport connection. Before the arrival he did not know arrival time of connection and in case of the transfer to another connection during his journey he does not know how long he will be wait on the arrival of another connection. In this manner of travelling the passenger does not know timetable at the time when he arrive to the stop of urban mass transportation. If we predict that there is secured periodic and precision of transport than passengers waiting meantime on the transport connection equals mean value of transport interval. This manner of passenger decision mainly utilize at the travelling in urban mass transportation.

Planned manner of passenger decision at travelling use mainly passenger, which are affected by accurate arrival time to the destination of their journey whereupon they find out time of departure transport connection before their arrival to the stop. In term of passenger psychic planned man- 
ner of passenger decision is preferable because passenger choose the manner of travelling by himself and according with his requests on speed, time or quality of transfer. Passenger tries adapting his arrival to the stop of urban mass transportation by decreasing waiting time to the transport connection. Passenger's arrival probability at stop in this case has unsymmetrical discreet distribution in the transport interval, which can be simulated in agreement with Poisson's distribution, [2]. We can apply a following formula to the calculation of passenger's arrival probability in the time " $t$ ":

$p(t)=\frac{\mu^{t}}{t !} e^{-\mu}$

$p(t)$ - passenger's arrival probability to the stop in the time " $\mathrm{t}$ ",

$\mathrm{t}$ - time between the passenger's arrival to the stop and departure of transportation line,

$\mu$ - parameter of Poisson's distribution (in our case), $t_{c}$ - average waiting time of passenger to the transportation line (on base measured at majority our cities equals the overhead quartile 4,4-4,9 min.).

\section{Transport lines harmonization in the selected transport junction of the transport time mini- misation aspect}

At harmonization we regard given set of transportation lines, which drives on the selected transportation network. It was needs to search transportation times of passengers from the beginning stop up to the final stop. We tried to search of such routes so that the passenger can transfer from the source till his destination for the shortest time and with the minimum number of transmissions. Transportation network in general makes a graph $G=\left(V, H, t_{i j}, t_{i}^{\alpha}\right)$, where set of stops will represent set of vertices $\left(\nu_{1}, \nu_{2^{\prime}}\right.$ $\left.\ldots, \nu_{\mathrm{n}}\right)$, direct transportation lines between vertices will represent us a set of edges $H=\left\{\left[v_{i}, v_{j}\right] ; v_{i}, v_{j} \in V\right\}$ distance between vertices "i“ and "j" in the time units [min] will be $t_{i j}$ and stopping time of means of transport at the stop will be $t_{i}^{\alpha}$ [3]. In our case we needed modify a graph of transportation network so we added auxiliary vertices for the transport junctions $\left(v_{i}^{p}\right.$ - point, when means of transport arrive on the stop and $v_{i}^{\alpha}$-point, when means of transport departure from the stop) and edges ( $t_{i}^{\alpha}$ - stopping time of means of transport at the stop). As we were thinking with a time between stops according to the timetable the edge represented stopping of means of transport at the stops had a zero value. In the case that the vertex $\nu_{i}$ does not make transport junction we will suppose that the transportation line continue in the ride without the stop. For the transport junction where the passengers makes a transmission between the transport lines "n" and "m", vertices jumper lead $v_{i}^{p n}$ of the one line and the second line represents the edge $t_{i}^{(n, m)}$, which value is transfer time from the line "n" to the line " $\mathrm{m}$ " in the transport junction "i". In Fig. 4 is shown how the graph modification looks like in the vertex when two transport lines crossing and transmission of passengers between those lines.
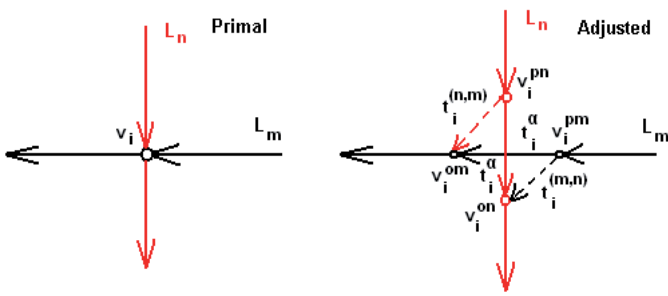

Fig. 4: Graph adjustment in the vertex at two transport lines crossing.

If two transport lines the same means of transport arrive from two different directions, meets in one vertex and continue in the same way in that case we will predict that the passengers do not transmission and we modify the graph as is shown in the Fig. 5.
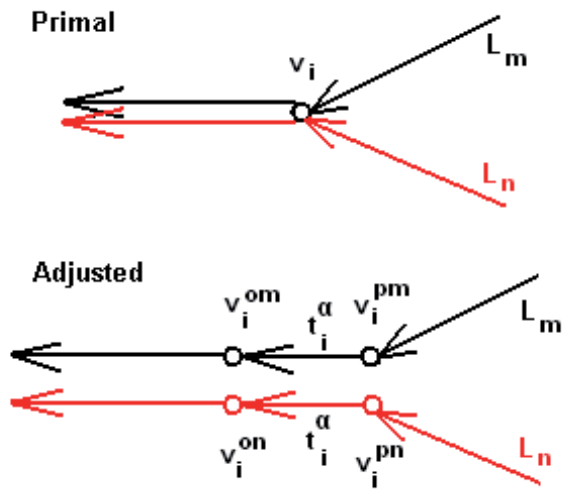

Fig. 5: Graph adjust at parallel transport lines.

Also we will think that passenger come randomly to the stop without knowledge of timetable. Interval between transportation lines on the specific line we will indicate as $\tau$. Arrival time of transportation line on the line respond to the rectangular distribution 
at the time interval $(0, \tau)$. For the random quantity ${ }_{\text {II }} \mathrm{x}^{\prime \prime}$ of this distribution there is characteristic density of distribution $f(x)=\frac{1}{\tau}$, for $x \in(0, \tau)$ and $f(x)=0$ for the others ${ }_{\text {„X}} \mathrm{x}$. In assumption accurate observance of timetable we will use average value of random (which equals the value $\frac{\tau}{2}$ ) for waiting average time of passenger without the knowing of timetable on given line at any of stops where that line come through. In our case generally will be apply the relation $t_{i}^{(m, n)}=\frac{\tau_{n}}{2}$ what means that the transmission time of the line " $\mathrm{m}$ " to the line " $\mathrm{n}$ " equals half time of the interval between the transportation lines at the line "n". For the calculation transfer time from the source to the destination of transport with transmission in one transport junction between two lines $T_{n, m}$ we use formula:

$T_{n, m}=\sum_{i=1}^{k} t_{i j}^{k(n)}+t_{i}^{(n, m)}+\sum_{i=k}^{l} t_{i j}^{l(m)}$

where, $\sum_{i=1}^{k} t_{i j}^{k(n)}$ is transportation time of passenger from the beginning stop to the transport junction " $\mathrm{k}^{\prime \prime}$ at the line ${ }_{\text {"n}} \mathrm{n}$, $t_{i}^{(n, m)}$ is transmission time from the line ${ }_{\text {" }} \mathrm{n}^{\prime \prime}$ at the line " $\mathrm{m}^{\prime \prime}$ and is transportation time of passenger from the transport junction " $\mathrm{k}^{\prime \prime}$ to the final stop at the line "m". By the investigation transfer times for all combinations of transport connections there was found that the transport junction "SOU Dopravné" is most useful for the transmission of passengers between lines from direction "Station square" to the monitor city areas. In the opposite direction there is the most useful transport junction "Námestie osloboditelov". These representations apply equally for peak time also for saddle time. The goal of the harmonization is to get a passenger in the shortest time and with the least sums of transfer from the source into the destination of his journey. For the solution of transportation network optimisation there was define following initial conditions:

- Tramway lines making basic transportation network will be have invariable intervals according to timetable.

- There will be optimised only bus lines, which create additional transportation networks destined to the thinking city areas.

- For transport junction will be consider a stop named "SOU Dopravné".

- Transport line knotting in the transport junction during the peak time must be in the interval 1 - 5 minutes.

- Transport line knotting in the transport junction during the saddle time must be in the interval $1-10$ minutes.

Of all thinking transport lines driving on the thinking transportation network in the peak time and saddle time there was needed make harmonization of four transport lines during the weekdays and two transport lines during the weekend or bank holidays. There was situations when there was very long waiting times (15 minutes) for the next transportation line (for the transmission), or when the next transportation line leaves the transport junction before or in the same time like arrive the transportation line drive on the basic transportation network. After we made harmonization there was compliance all initial conditions. Transportation lines knotting in the transport junction not exceed 5 minutes neither during peak time or saddle time provided the transportation lines will be driven reliable according to timetable.

\section{Acknowledge}

If we want at the present time improve the environment and traffic operations in the cities we should expend all effort. Public transport system must be mainly safety as well as it has to provide periodic transport, adequate sustained speed, minimum sums of transmission, comfort of transport and small blackout time in the periodic transport. It is very important to make a harmonization of transport lines because in the case of long waiting times of passengers on the transportation lines in the transport junctions they start look for an another way of transport. This will cause leaving the passengers of the public mass transportation. Even in the sphere of transport is valid an old good saying: "Our customer is our boss". Transporters should look at the transport by the eyes of passengers and should make so conditions that on the one side they should attract more passengers to the transport and at the second side to show a profit of making their activities

\section{References}

[1] Přibil P., Svítek M.: Inteligentní dopravní systémy, technická literatúra BEN, Praha 2001, ISBN 80-7300-029-6.

[2] Surovec Pavel: Hromadná osobná doprava, Žilinská Univerzita, Žilina, 2007, ISBN 978-80-8070-686-9.

[3] Branická M., Stacho M.: Model MHD a optimalizácie času premiestnenia cestujúceho, In: Doprava a spoje - internetový časopis Fakulty prevádzky a ekonomiky dopravy a spojov Žilinskej Univerzity v Žiline, [online]. 2007. Dostupné na 
internete: http://fperdas.uniza.sk/dopravaaspoje/2007/1/ branicka.pdf.

[4] Bigoš,P., Onofrejová,D:Design of Simulation Model and Experimenting with Model in Order to Solve Logistics Issnes in Healthcare Sector. Acta Mechanica Slovaca,No 4/2009, s. 28-38, ISSN 1335-2393.

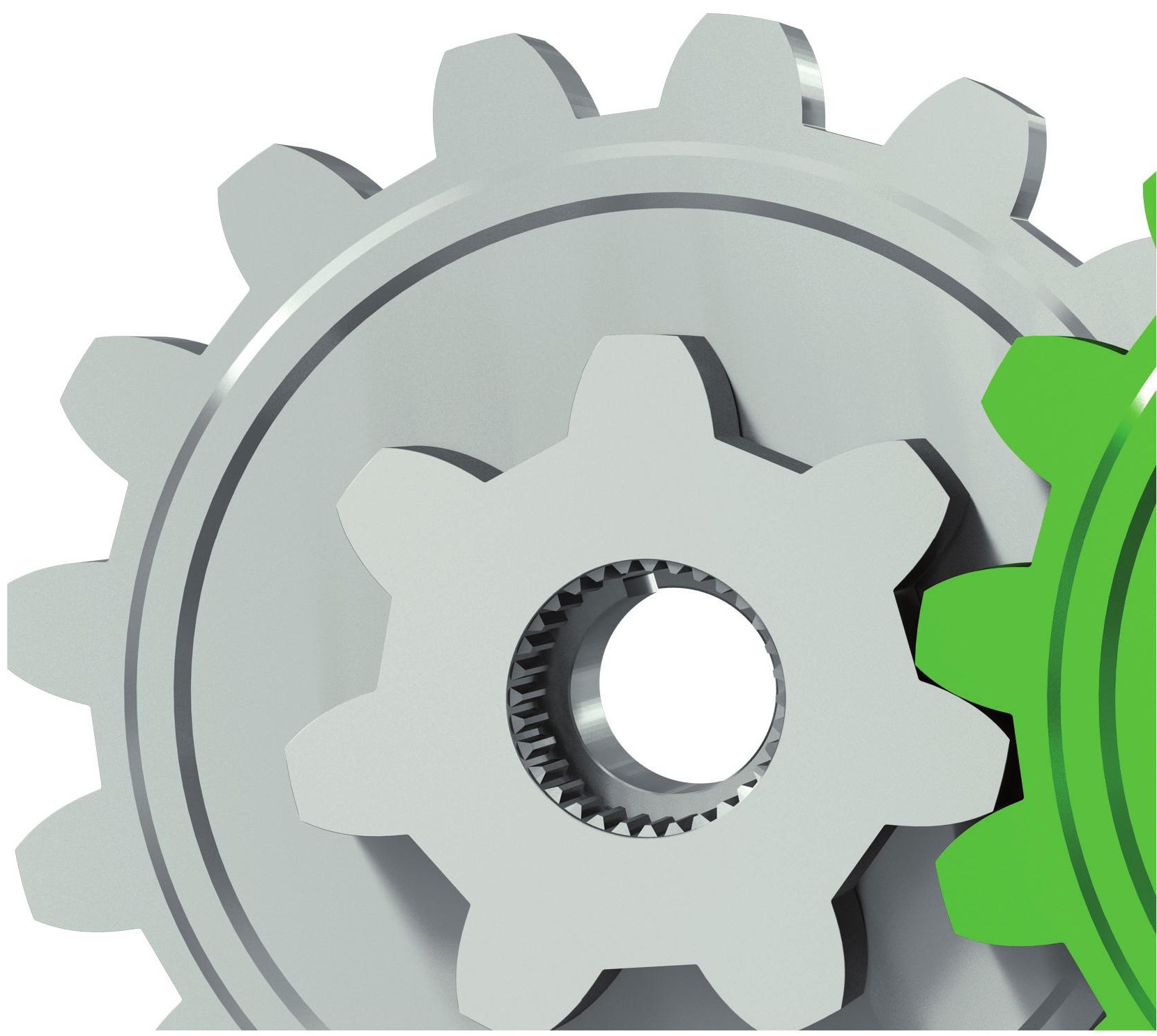

